\title{
Recognising developmental coordination disorder in Foundation Phase classrooms
}

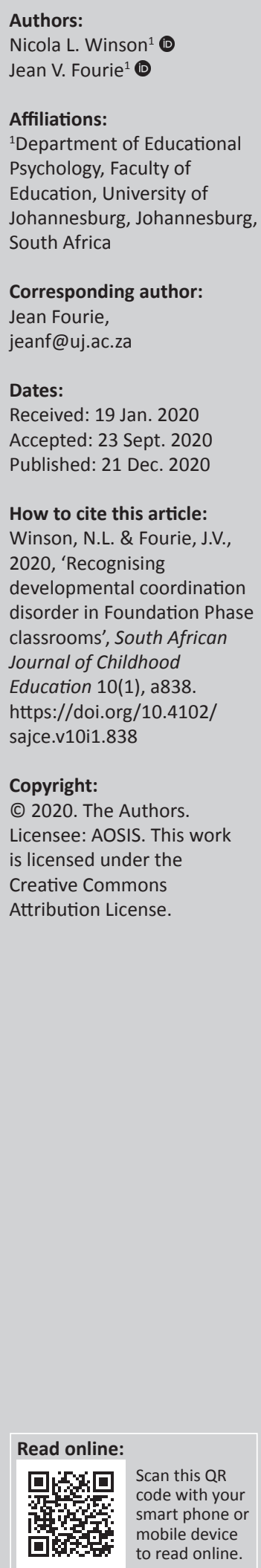

Background: Developmental coordination disorder (DCD) is a neurodevelopmental motor disorder affecting $5 \%$ to $6 \%$ of children globally. The motor skills deficit associated with DCD is characterised by its impact on academic productivity, activities of daily living and play. Although the Department of Education's (2014) policy on screening, identification, assessment and support (SIAS) calls for teachers to be the first line of identification of learning barriers, teachers are often unaware of the characteristics of DCD and have difficulty in recognising the condition.

Aim: This study explored the recognisable characteristics of DCD, which Foundation Phase learners may display, to assist teachers in effectively recognising this potential learning barrier.

Setting: Occupational-, speech- and physiotherapists, remedial teachers and educational psychologists working with Foundation Phase learners in Johannesburg, South Africa, participated in the study.

Methods: Within a generic qualitative design, semistructured interviews were conducted. The interviews were audio-recorded, transcribed and the content coded into meaningful units to derive themes relating to the study's aim.

Results: Developmental coordination disorder has multidomain and cascading characteristics. Learners present with fine and gross motor challenges, difficulties with social interaction, frustration and associated aggression, and task avoidance. Challenges regarding planning, sequencing, organisation, slow task completion and difficulties with academic skills may be observed.

Conclusion: Developmental coordination disorder is recognisable in Foundation Phase classrooms, provided that teachers carefully observe learners' behaviour. Early recognition of symptoms may lead to accurate diagnosis, increased understanding and the provision of appropriate supportive interventions.

Keywords: developmental coordination disorder; dyspraxia; Foundation Phase; neurodevelopmental disorder; qualitative research.

\section{Introduction}

Developmental coordination disorder (DCD) is a chronic neurological condition that influences movement and coordination, resulting in delayed gross and fine motor skills and general clumsiness (Missiuna et al. 2006). Developmental coordination disorder is often misunderstood and misdiagnosed and remains an enigma to many educators and medical professionals (Gibbs, Appleton \& Appleton 2007). Developmental coordination disorder is recognised by the American Psychiatric Association as a neurodevelopmental disorder, which affects 5\% to $6 \%$ of schoolgoing children (APA 2013; Marien et al. 2010; Sadock, Sadock \& Ruiz 2015). It can, therefore, be considered a common neurodevelopmental disorder in children of school-going age. Although teachers are not permitted to make a DCD diagnosis, they are often responsible for the initial identification of the symptoms of barriers to learning, such as DCD, and referral to the appropriate healthcare professional. However, to be able to recognise DCD in Foundation Phase classrooms, teachers' need to be aware of the possible signs and symptoms, which may be observed in learners.

\section{Developmental coordination disorder}

The lack of consensus regarding the name by which to call the observed motor challenges has resulted in the use of the terms 'minimal cerebral palsy,' 'dyspraxia,' 'minimal brain dysfunction' and 'clumsy child syndrome' by different professions (APA 2013). At the International Consensus 
Meeting on Children and Clumsiness, held in Ontario, Canada, in 1994, the term 'developmental coordination disorder' was accepted (Polatajko, Fox \& Missiuna 1995).

Although classified as a motor disorder, the condition's impact extends beyond the physical domain. The multidomain impact of DCD is acknowledged in the Diagnostic and Statistical Manual of Mental Disorders (APA 2013). There are four diagnostic criteria for DCD. Firstly, the acquisition and execution of skills requiring coordination are substantially below what would be expected of an individual of that chronological age. Secondly, there is a motor skills deficit that considerably interferes with activities of daily living and impacts on academic productivity, leisure and play. Thirdly, the above-mentioned symptoms must be shown during the early developmental period and finally, the symptoms may not be because of intellectual impairment, visual impairment or another neurological condition impacting on movement ability (APA 2013).

Despite primarily being a motor disorder, the effects of DCD reach further than a motor coordination control difficulty. Academic challenges and social difficulties may arise from decreased participation in leisure and play activities (APA 2013; Sadock et al. 2015). Learners with DCD are also at greater risk of developing emotional and behavioural challenges (Sadock et al. 2015). Thus, a multidisciplinary network of supportive educators and therapists are needed for targeted interventions (Fourie 2018) as individuals with DCD have their own unique profiles of challenges and strengths (Jasmin et al. 2018).

Despite the multidomain impact of DCD, the focus of research is often placed on a medical understanding of the disorder and the associated symptoms. Research on DCD about education remains sparse, especially when compared with research on other neurodevelopmental disorders (Edmonds 2013; Gomez \& Sirigu 2015).

Childhood development encompasses physical, cognitive, academic, social, behavioural and emotional facets (Finestone 2004; Martorell, Papalia \& Feldman 2013). Physical development includes coordination, fine and gross motor abilities, sensory skills and health. Cognitive or intellectual development includes perceptual skills, attention, language, reasoning and problem-solving. The social, emotional and behavioural domain, also referred to as the psychosocial domain, includes emotional development, social interactions, awareness of right and wrong and the development of suitable behaviours (Finestone 2004; Martorell et al. 2013).

Although each domain has been separately described, the development of each one influences all the others (Surgen 2018). Human development is an integrated and interactive process in which all domains of functioning are interdependent (Donald, Lazarus \& Moolla 2014). Therefore, when considering the impact of DCD, it is necessary to consider all domains of functioning - the physical, social, emotional, behavioural, cognitive and academic.

Physical challenges experienced by learners with DCD in the Foundation Phase include both fine and gross motor difficulties. Motor activities are performed with great difficulty and often without success (Missiuna et al. 2007). Developmental coordination disorder is a syndrome characterised by clumsy or inaccurate motor skills and results in difficulty in conceptualising, planning and executing movements (Case-Smith 2005). Learners with DCD experience challenges in learning and automatising gross and fine motor activities (Schott, El-Rajab \& Klotzbier 2016). Slowness in executing motor tasks, organising their body to perform tasks, answering questions and peer relations may also prove challenging for learners with DCD (Farmer, Echenne \& Bentourkia 2016). The slow rate of task completion may be the initial characteristic observed in learners with DCD (Farmer et al. 2016). Although these learners experience difficulties with motor skills and coordination, they can learn motor skills, given the necessary time and practice (Biotteau, Chaix \& Albaret 2016; Pieters et al. 2012).

For many children presenting with DCD, activities such as getting dressed or tying shoelaces continue to require special attention, despite the amount of time and effort spent practising the skill or activity (Biotteau et al. 2016; Zwicker et al. 2018). The lack of age-appropriate gross and fine motor skills in learners with DCD results in challenges with manual dexterity (including handwriting, cutting and assembling puzzles), ball skills and balance (Prunty et al. 2016a; Sadock et al. 2015). As a result of the motor difficulties, challenges with tasks such as writing, cutting, eating with utensils, fastening buttons and zips and tying shoelaces may be present (Case-Smith 2005). According to Farmer et al. (2016), $97 \%$ of their participants with DCD had abnormal handwriting. At school, learners are expected to write notes, copy information from the board and write tests. These activities tend to be time-consuming, complicated and messy for learners with DCD (Zwicker et al. 2018). Handwriting difficulties not only impact on the neatness of the produced work but also on the composition of the written material (Prunty et al. 2016b).

Learners with DCD may also have difficulty coordinating their eyes to track words on a page and focus on moving objects. They may find it challenging to copy accurately from the blackboard, as this requires the shifting of their gaze from a shorter to a longer distance. Turning pages in a book and organising desk space and personal belongings may also be a struggle (Kranowitz 2005). They may also struggle with directionality (Kranowitz 2005). Speech articulation may also prove challenging as they may have difficulty moving their oral muscles to produce the necessary sounds (Case-Smith 2005; Farmer et al. 2016).

Learners manifesting DCD may have difficulties in perceiving, sequencing, organising and carrying out actions or movements and may appear to be clumsy or accident 
prone (Kranowitz 2005). They tend to have an awkward or abnormal gait when compared with their typically developing peers (Sadock et al. 2015) and less muscle mass (Yam \& Fong 2018). As a result, sporting activities may become challenging. Simply maintaining their posture may also prove difficult because of less efficient visual control (Speedtsberg et al. 2017).

The participation of learners with DCD in leisure and play activities, as well as activities of daily living and academic tasks, tends to be hampered by their struggle with coordination and motor skills. This in turn increases their risk of developing psychological and social difficulties (Prunty et al. 2016a; Sadock et al. 2015). In a study on 12-year-olds' experiences of living with DCD, a range of negative emotions were reported regarding frustrations with activities of daily living and general academic performance (Zwicker et al. 2018). Participation in school sports and social activities resulted in the strongest negative emotions (Zwicker et al. 2018).

Teachers claim that learners with DCD have significantly more emotional and behavioural problems than their typically developing peers (Crane, Sumner \& Hill 2017; Van Den Heuvel et al. 2016). These learners were also at greater risk of developing emotional and behavioural problems than their typically developing peers. They may feel inadequate because of their motor skills deficits (Le Roux 2018). Furthermore, the learner's gender may play a role in the emotional challenges they face. For boys, the challenges around participating in sporting and physical activities may result in a negative self-concept and reduced social engagement. Difficulties in self-care skills, such as applying makeup, may affect girls' self-perception (Li et al. 2018).

Tasks that their age-related peers can easily accomplish are often difficult for learners with DCD, who find each day full of frustrations and disappointments, frequently leading to anger or tearful outbursts (Farmer et al. 2016; Missiuna et al. 2007). As learners with DCD grow up, they become increasingly aware of their limitations and inability to keep up with their peers in terms of motor skills. Social engagements are affected. These learners find it difficult to get the timing right, or to know when and how to initiate conversation, to interject in the dialogue and struggle to keep up with the pace of the discussion (Le Roux 2018). Learners also found it difficult to express their opinions to their peers or to be assertive (Chang 2018). Learners with DCD may also find it difficult to use motor and verbal skills simultaneously, which negatively affects their ability to participate in many social games with rules (Le Roux 2018). Consequently, their participation in leisure activities decreases and they may find themselves isolated from their peer group on the playground (Missiuna et al. 2007). Learners with DCD are also at risk of being teased and bullied (Missiuna et al. 2007; Zwicker et al. 2018). Repeated failure at tasks tends to reduce their sense of self-efficacy and can lead to the development of a negative self-image (Missiuna et al. 2007). Difficulties with communication because of poor oral-facial muscle coordination may inhibit self-expression. This may result in the learners becoming frustrated and feeling isolated or acting out aggressively or angrily (Farmer et al. 2016). Disruptive behaviour and other behavioural problems often co-occur with DCD (APA 2013). Also, such learners often feel anxious, especially at school and in social interaction, as they tend to be overwhelmed by the academic and social expectations placed upon them (Missiuna et al. 2007). Learners with DCD may even find themselves inaccurately labelled as having an intellectual delay, having attention deficit disorder or being on the autistic spectrum because of their motor challenges in all domains of functioning (Farmer et al. 2016).

This study explored the symptoms of DCD that teachers may observe in Foundation Phase classrooms. If they are better able to recognise the symptoms of DCD, teachers could provide appropriate classroom-based support and make the necessary referrals.

\section{Research methods and design}

To explore the observable challenges faced by Foundation Phase learners with DCD, a generic qualitative study was undertaken, using an interpretive paradigm to gain greater understanding of the phenomenon (Caelli, Ray \& Mill 2003).

\section{Setting and participants}

To gain a holistic understanding of the symptoms of DCD, occupational therapists, remedial teachers, physiotherapists, speech therapists and educational psychologists were purposefully selected and invited to participate in the study. These multidisciplinary professionals work in mainstream schools, remedial schools and private practices with learners who are diagnosed with DCD.

Therapists and remedial teachers were contacted through their private practice or school websites, which indicated their interest in working with children diagnosed with DCD or neurodevelopmental barriers. Additional participants were contacted through snowball sampling. A total of 48 professionals were invited to participate in the study. A total of 12 individuals consented to participate in the study. All the participants have formal qualifications in their field of expertise and more than 5 years' experience (Table 1 ).

\section{Data collection and analysis}

Individual semi-structured individual interviews were conducted with each participant to explore their experiences and views on how DCD can present within the Foundation Phase classroom setting. All the domains of functioning were explored with each of the participants regardless of their areas of expertise. 
TABLE 1: Participant details.

\begin{tabular}{|c|c|c|c|}
\hline Participant & Highest qualification & $\begin{array}{l}\text { Experience } \\
\text { (years) }\end{array}$ & Place of work \\
\hline $\begin{array}{l}\text { Remedial teacher } 1 \\
\text { (RT1) }\end{array}$ & $\begin{array}{l}\text { Diploma in remedial } \\
\text { education }\end{array}$ & 28 & $\begin{array}{l}\text { Mainstream and } \\
\text { remedial schools }\end{array}$ \\
\hline $\begin{array}{l}\text { Remedial teacher } 2 \\
\text { (RT2) }\end{array}$ & B.Ed Honours & 10 & Remedial school \\
\hline $\begin{array}{l}\text { Educational } \\
\text { psychologist } 1 \text { (EP1) }\end{array}$ & $\begin{array}{l}\text { M.Ed (Educational } \\
\text { Psychology) }\end{array}$ & 10 & Mainstream school \\
\hline $\begin{array}{l}\text { Educational } \\
\text { psychologist } 2 \text { (EP2) }\end{array}$ & $\begin{array}{l}\text { M.Ed (Educational } \\
\text { Psychology) }\end{array}$ & 8 & $\begin{array}{l}\text { Private practice and } \\
\text { mainstream schools }\end{array}$ \\
\hline $\begin{array}{l}\text { Educational } \\
\text { psychologist } 3 \text { (EP3) }\end{array}$ & $\begin{array}{l}\text { M.Ed (Educational } \\
\text { Psychology) }\end{array}$ & 10 & $\begin{array}{l}\text { Private practice and } \\
\text { mainstream school }\end{array}$ \\
\hline $\begin{array}{l}\text { Speech therapist } 1 \\
\text { (ST1) }\end{array}$ & $\begin{array}{l}\text { B.A (Speech \& Hearing } \\
\text { Therapy) Honours }\end{array}$ & 14 & Remedial schools \\
\hline $\begin{array}{l}\text { Speech therapist } 2 \\
\text { (ST2) }\end{array}$ & $\begin{array}{l}\text { Bachelor in Speech-Language } \\
\text { Pathology and Audiology }\end{array}$ & 10 & Remedial school \\
\hline $\begin{array}{l}\text { Occupational } \\
\text { therapist } 1 \text { (OT1) }\end{array}$ & B.A (Occupational Therapy) & 27 & $\begin{array}{l}\text { Private practice and } \\
\text { mainstream schools }\end{array}$ \\
\hline $\begin{array}{l}\text { Occupational } \\
\text { therapist } 2 \text { (OT2) }\end{array}$ & B.A (OT) & 16 & $\begin{array}{l}\text { Private practice and } \\
\text { mainstream schools }\end{array}$ \\
\hline $\begin{array}{l}\text { Physiotherapist } 1 \\
\text { (PT1) }\end{array}$ & B.Sc (Physiotherapy) & 22 & Private practice \\
\hline $\begin{array}{l}\text { Physiotherapist } 2 \\
\text { (PT2) }\end{array}$ & B.Sc (Physiotherapy) & 10 & $\begin{array}{l}\text { Mainstream and } \\
\text { remedial schools }\end{array}$ \\
\hline $\begin{array}{l}\text { Physiotherapist } 3 \\
\text { (PT3) }\end{array}$ & B.Sc (Physiotherapy) & 7 & $\begin{array}{l}\text { Private practice and } \\
\text { mainstream schools }\end{array}$ \\
\hline
\end{tabular}

However, as might be expected, the participants tended to give greater insights into domains related to their specific areas of expertise.

With the informed consent of the participants, the interviews were audio-recorded. The recordings were transcribed verbatim. The transcriptions were inserted into a tabular format with each meaningful unit, consisting of a sentence or short paragraph, segmented into its own row in the table. Each row was numbered to ensure that the units could be referred to their context. Units relating to the aim of the study were highlighted and assigned a code. Each coded unit from each of the tabled transcripts was then transferred into a spreadsheet so that meaningful units from each participant could be compared. The assembled meaningful units were then grouped according to the domains of functioning to derive common themes.

\section{Ethical consideration}

Ethical approval was received from the University of Johannesburg Education Research Ethics Committee. Informed consent was received from each participant before the interviews were conducted. The participant's rights to anonymity and confidentiality were upheld during the study by using a coding system, which referred to the participant's profession and participant number rather than name. Ethical Clearance Number: 2017-073.

\section{Results}

Four main themes emerged from the data analysis. The first theme describes general observations made by the participants. The second theme explains the symptoms and characteristics of DCD that manifest in the physical domain. The third theme considers the social, emotional and behavioural domains, whilst the final theme explores cognitive and academic difficulties displayed.

\section{Theme 1: General understanding of developmental coordination disorder}

To be able to identify DCD within the classroom so that the necessary support can be provided, teachers need to recognise the existence of DCD and understand its impact on a learner's life. Educational psychologist 1 reasoned that, 'Maybe understanding what dyspraxia is, maybe that's the biggest thing of all of this' (EP1, 10 years of experience, mainstream school).

The lack of understanding of DCD is not limited to teachers, but includes all professions:

'We by and large get an ADHD diagnosis ... but, in a classroom you can see they're not impulsive, they're just uncomfortable or prickly or thorny or their planning is a bit off.' (TR2, 10 years of experience, remedial school)

The observations made by the teacher in the classroom may even contradict an already received diagnosis. Along with the understanding of the disorder comes an understanding that every learner is a unique individual who may experience different challenges and have varying strengths. Speech therapist 1 explained that 'Every single child is different, you have to go case by case and you have to judge each child individually and make a plan for each child'. Even within a group of learners with DCD, a variety of different symptoms may be displayed.

\section{Cascade effect}

Developmental coordination disorder is not a disorder that impacts physical appearance. As a result, it may be easily overlooked and misunderstood. This lack of understanding may result in a cascade of challenges:

'Looking at someone, you don't know that they have dyspraxia and so it may be easy to dismiss it or not understand and therefore not be empathetic, and so that may bring about behaviour that is not always great.' (EP1, 10 years of experience, mainstream school)

Although the term 'developmental coordination disorder' appears to emphasise the coordination or physical aspect of the disorder, the cascade effect and multidomain impact of DCD was stressed by all participants:

'There are a lot of aspects in terms of the socialisation, the academic - and then it also rubs on the emotional side. The playground [issues] include difficulty with skills that other kids find easy, swinging, kicking balls ... Also, in the classroom we find fine motor difficulties depending on the type of dyspraxia, the ideomotor, the sequencing, the processing ideation is also very difficult and usually [they are] very smart kids. So, the academics are disturbed. And from an emotional point of view, they really, really start to become introverted and frustrated.' (RT2, 10 years of experience, remedial school)

The recognition of DCD is not limited to a single domain but can be observed in every domain of functioning. Learners have difficulty with physical skills, and often develop secondary symptoms related to social, emotional and academic functioning. 
TABLE 2: Fine motor challenges.

\begin{tabular}{|c|c|c|c|c|c|c|c|c|c|c|c|c|}
\hline Fine motor challenge & RT1 & RT2 & EP1 & EP2 & EP3 & ST1 & ST2 & OT1 & OT2 & PT1 & PT2 & PT3 \\
\hline Art activities & $x$ & - & $x$ & - & - & - & - & $x$ & - & - & - & $x$ \\
\hline Threading & - & - & $x$ & - & - & - & - & - & $x$ & - & - & - \\
\hline Pegboards & - & - & $x$ & - & - & - & - & - & - & - & - & - \\
\hline Opening containers & - & - & - & - & - & - & - & - & - & $x$ & - & - \\
\hline Cutting & $x$ & $x$ & $x$ & - & - & - & - & $x$ & $x$ & - & $x$ & - \\
\hline Pencil grip & - & - & - & - & - & - & - & $x$ & $x$ & - & $x$ & - \\
\hline Buttons and laces & - & $x$ & - & $x$ & - & - & - & - & - & $x$ & - & - \\
\hline Handwriting & $x$ & $x$ & $x$ & $x$ & $x$ & - & - & - & - & $x$ & $x$ & - \\
\hline Speech & $x$ & - & - & - & - & $x$ & $x$ & $x$ & $x$ & $x$ & - & - \\
\hline Eating & - & - & - & - & - & - & $x$ & - & - & - & - & - \\
\hline
\end{tabular}

RT1, Remedial teacher 1; RT2, Remedial teacher 2; EP1, Educational psychologist 1; EP2, Educational psychologist 2; EP3, Educational psychologist 3; ST1, Speech therapist 1; ST2, Speech therapist 2; OT1, Occupational therapist 1; OT2, Occupational therapist 2; PT1, Physiotherapist 1; PT2, Physiotherapist 2; PT3, Physiotherapist 3.

\section{Theme 2: Challenges in the physical domain}

Within the Foundation Phase, the motor challenges faced by learners with DCD may be more evident than in later educational phases:

'It's particularly challenging in the Foundation Phase classroom because they're having to learn the mechanical skills. For us, it's very automatic, but for a child of that age it's still very purposeful and there is a lot of motor planning involved.' (EP2, 8 years of experience, private practice and mainstream schools)

\section{Fine motor challenges}

All the participants described fine motor challenges that are observable in the Foundation Phase classroom (Table 2).

Handwriting and speech difficulties were observed most often amongst learners presenting with DCD. When describing handwriting, EP2 explained that:

'For us it's very automatic but for a child of that age it's still very purposeful and there is a lot of motor planning involved. I think for them it's very hard.' (EP2, 8 years of experience, private practice and mainstream schools)

Physiotherapist 1 added:

'It's harder for them to form the shapes so it's not as tidy.' (PT1)

Motor coordination challenges may be observed in the learner's speech. According to ST2:

'The motor planning difficulties which I would see would be in the sequencing of [the] oral structures to produce sounds, and to sequence those sounds together to make words, and those words to become sentences. The more multisyllabic a word is, the harder it is to plan and sequence those movements.' (ST2, 10 years of experience, remedial school)

Learners may also become reluctant to participate in class discussions and ask questions (RT1); may have difficulty navigating the timing of conversations and knowing when to join in (OT2) and may find that they are often misunderstood (PT1).

\section{Gross motor challenges}

Difficulties with gross motor coordination and execution can be observed by Foundation Phase teachers. These difficulties include challenges in participating in sporting activities and physical education lessons, being clumsy and having difficulty maintaining posture when sitting. According to ST1: 'In sports they would be laughed at. They try to do this or that activity and they don't manage to do it and kids are mean.' (ST1, 14 years of experience, remedial school)

Teachers identified some of the challenges:

'They're very clumsy, they fall over their desk, they fall off their chair, they fall over their bag ... They're very disruptive because of the fact that they are clumsy.' (OT1, 27 years of experience, private practice and mainstream schools)

Learners with DCD also struggle to coordinate the use of objects:

'Another thing is dropping of pencils and pencil cases. Whenever I walk into the classroom, the teachers always want to freak out. Those kids who have been diagnosed as dyspraxic, their pencil cases are always on the floor.' (OT1, 27 years of experience, private practice and mainstream schools)

Remedial teacher 1 added that:

'Art lessons could be quite a trial. With the clumsy child they would be constantly knocking things over, [like] the bottles of paint, so yes, for them it was difficult, and of course irritating to the other children.' (RT1, 28 years of experience, mainstream and remedial schools)

The tendency towards clumsiness is observable to teachers and can also frustrate peers.

Difficulty in maintaining an upright posture was also identified. RT1 observed a '... sloppy posture ...' (RT1,28 years of experience, mainstream and remedial schools) while PT1 described a quick onset of fatigue and illustrated the cascade effect caused by learners' poor posture. Teachers said they tend to, '... struggle to maintain their posture ... and this in turn affects their concentration. It affects their handwriting so, it's all a cascade effect.' (PT1, 22 years of experience, private practice).

\section{Theme 3: Challenges in the social, emotional and behavioural domain}

\section{Lowered self-esteem}

Occupational therapist 1 indicated that 'their self-esteem is normally really low because they've been labelled as clumsy, 
naughty, silly, all of those things ...' (OT1, 27 years of experience, private practice and mainstream schools). During the Foundation Phase period, learners become increasingly aware of their competencies. Educational psychologist 2 explained that:

'Looking at it from like Erikson's stage development, it is the stage where they start to have a perception of how they are doing compared to their peers in terms of capabilities.' (EP2, 8 years of experience, private practice and mainstream schools)

Learners with DCD often struggle to master the skills that their peers are competent at. Teachers may observe them struggling to participate in sporting activities and making use of playground equipment. This may result in their being left out of games. Lagging behind their peers may further lower their self-esteem learners with DCD may also feel as although they are different from their peers (EP1; PT1). This may in turn reduce their confidence and reduce their willingness to participate in social interactions (EP1; EP3).

\section{Social challenges}

Occupational therapist 1 explained that 'I've noticed that a lot of them get bullied ... maybe because they're clumsy and not really the performers in sport, they're not academically doing that well' (OT1, 27 years of experience, private practice and mainstream schools). This may be exacerbated by poor speech as they may be misunderstood and teased by their peers (ST1). Speech therapist 2 pointed out that:

'Expressively, we're human beings and we connect, we're built to connect. And to not be understood when you know what you want to say but you're struggling to organise it.' (ST2, 10 years of experience, remedial school)

Remedial teacher 1 further commented that the lack of understanding may result in reluctance to participate in social interactions and the learner may even '... withdraw from social contact with children, or isolate himself, just avoid being with the other children' (RT1, 28 years of experience, mainstream and remedial schools).

\section{Emotional and behavioural challenges}

Physiotherapist 3 pointed out that:

'Some of them do become naughty, or aggressive, because "nobody understands me." It's almost like a way of saying, Hello, here I am, can somebody please see me?' (PT3, 7 years of experience, private practice and mainstream schools)

The participants identified frustration, anxiety, high family stress, avoidance and aggression in Foundation Phase learners with DCD (Table 3).
Remedial teacher 2 explained that 'Frustration, frustration, high levels of frustration; frustration is the biggest thing' (TR2, 10 years of experience, remedial school). Learners with DCD may experience frustration as a result of the discrepancy between their understanding and their ability to physically perform (RT2), not being able to accomplish tasks that they feel they should be able to do (EP1, EP2 and OT1) not being understood when speaking (ST1) and their cognitive ability appearing to be less than what it is (ST2). However, the frustration does not end with the learner - the teacher and peers may also experience frustration. Remedial teacher 1 pointed out that:

'There's irritation for the others by the clumsy child, because they get bumped into. Bumping them in the line, not intentionally, knocking things over, spilling things, losing things, you know, the child who never has a pencil. And that irritates the other children in the class, you know: "Can I borrow your pen?" that sort of thing. "Have you got a pencil for me?" It sets up a social dynamic.' (RT1, 28 years of experience, mainstream and remedial schools)

The frustration experienced may result in aggressive behaviour (EP1), which in turn may have a cascade effect. Physiotherapist 1 explained that:

'... They might smack their friends. And actually, they're not bad kids; they're just so frustrated ... They're suddenly in a whole world of trouble- more labels, more negativity... compounding the problem.' (PT1, 22 years of experience, private practice)

Speech therapist 2 reported that some of the learners receive medical and or psychological treatment for generalised anxiety disorder because of the extent of the anxiety that they experience during the school day. In addition, PT1 described the possible impact on academic performance because of the anxiety surrounding certain tasks or lessons becoming a distraction:

'So, the whole lesson before Physical Education, you don't absorb a single thing because you're just thinking: It's PE next, it's PE next, it's PE next. And so you miss out on the lesson.' (PT1, 22 years of experience, Private practice)

A learner with DCD may experience heightened anxiety in anticipation of the tasks that will be expected of them, especially if physical education, a challenging area, is on the timetable for the day.

Separation anxiety may also be observed, especially in the Foundation Phase. Occupational therapist 2 explained that:

'Separation anxiety is often a big thing with [learners with DCD] because the parents will often execute the plan. [The learner] has an idea and they want something, and the parents will do it. And

TABLE 3: Emotional and behavioural challenges identified by the participants.

\begin{tabular}{|c|c|c|c|c|c|c|c|c|c|c|c|c|}
\hline Emotional and behavioural challenges & RT1 & RT2 & EP1 & EP2 & EP3 & ST1 & ST2 & OT1 & от2 & PT1 & PT2 & PT3 \\
\hline Frustration & $x$ & $x$ & $x$ & $x$ & $x$ & $x$ & $x$ & $x$ & - & - & - & - \\
\hline Anxiety & - & - & $x$ & $x$ & - & - & $x$ & $x$ & $x$ & $x$ & $\mathrm{x}$ & - \\
\hline Family stress & - & - & - & $x$ & - & - & - & - & - & $x$ & - & - \\
\hline Avoidance & - & - & $x$ & $x$ & - & - & - & - & $x$ & - & $x$ & - \\
\hline Aggression & $x$ & - & $x$ & - & - & $x$ & - & - & $x$ & $x$ & - & $x$ \\
\hline
\end{tabular}

RT1, Remedial teacher 1; RT2, Remedial teacher 2; EP1, Educational psychologist 1; EP2, Educational psychologist 2; EP3, Educational psychologist 3; ST1, Speech therapist 1 ; ST2, Speech therapist 2; OT1, Occupational therapist 1; OT2, Occupational therapist 2; PT1, Physiotherapist 1; PT2, Physiotherapist 2; PT3, Physiotherapist 3. 
now when they go to school, they have to start doing things for themselves, and then they get anxious; and then separation anxiety increases and they become emotional.' (OT2, 16 years of experience, private practice and mainstream schools)

Learners with DCD may realise that it is their parents or caregivers who understands their needs and provides the support for the execution of their plans and desires. This heightens the anxiety created when separation from the parent or caregiver occurs.

Emotional and behavioural challenges observed within the classroom may also be attributed to stress experienced at home. Educational psychologist 2 explained that:

'Maybe dad was some sort of professional rugby player and now he has a dyspraxic son - what's happening around that, what are his views of his child? That plays into family issues; it filters into how the child is feeling about himself.' (EP2, 8 years of experience, private practice and mainstream schools)

In the classroom environment, teachers may observe learners with DCD avoiding tasks or appearing to react defiantly. However, this observed defiance may rather be a result of feeling overwhelmed or the fear of failure if they participate in an activity they can't perform:

"They will just be defiant and say, "I'm not doing it!" And it's not because they're being defiant, it's because it is just so overwhelming and the failure they will experience, they are not willing to go that route.' (OT1, 27 years of experience, private practice and mainstream schools)

\section{Theme 4: Academic challenges}

The participants observed a cascade effect, with the emotional impact of DCD affecting academic performance:

'The psycho-emotional effect of being behind. That's going to affect you cognitively. If you're permanently discouraged, you're going to believe that you can't do it and you're eventually not going to be able to do it.' (PT1, 22 years of experience, private practice)

Educational psychologist 2 added that:

'They start to feel like 'I'm not clever, I'm stupid'. Because their eyes are showing them that from what they see that they can't do what the other kids can do. But it's got nothing to do with how intelligent they are, it's the functional mechanical skills that are going wrong.' (EP2, 8 years of experience, private practice and mainstream schools)

\section{Planning, sequencing and organisational challenges}

Teachers observe that learners with DCD may have difficulty structuring, planning and prioritising tasks required for learning. Speech therapist 1 explained that:

'I think academically and cognitively, it all comes down to being able to get through a task. Plan a task. So, if you don't know where to start, you don't know how to proceed. It's going to be a problem throughout your school career. You're not going to get the task right if you've missed out steps, or done it the wrong way around.' (ST1, 14 years of experience, remedial school)
Learners find it difficult to follow instructions that require planning (PT2; RT1). Organisation may also prove to be challenging, desks may be messy and work poorly set out. Difficulties in planning, structuring and organising verbal tasks may further hamper written activities. Speech therapist 2 explains that 'If you're struggling to verbalise it in a sequenced order, then putting it down on paper, even despite the motor planning aspect of it, is difficult' (ST2, 10 years of experience, remedial school). In addition, EP1 adds that:

'Planning, even like a story - what comes first, and the middle and the end - those things take longer and require more structure and support than just saying "Go forth and write a story."' (EP1, 10 years of experience, mainstream school)

\section{Incomplete tasks}

Educational psychologist 3 explained, 'I think the biggest challenge when I see them, is around the output in terms of the written demands in the Foundation Phase' (EP3, 10 years of experience, private practice and mainstream schools). The teacher may recognise learners who they believe have the capacity to perform and yet are unable to do so.

'The teacher will give an instruction and the child will think: "I don't know where to start, and I don't know what is the next step, and I don't know what the end product should look like."' (OT2, 16 years of experience, private practice and mainstream schools)

Task completion may be further hampered by quick onset of fatigue. Physiotherapist 2 warned that it may appear that the learner is struggling to concentrate, 'Sometimes it looks like they're struggling with concentration but actually, it's not concentration, it's the gross motor - the physical side of things affecting the thinking' (PT2, 10 years of experience, mainstream and remedial schools).

\section{Difficulty with executive functioning}

Educational psychologist 3 pointed out that 'Planning is such an important part of executive functioning'. Occupational therapist 2 added, 'More complex things, like the higher executive thinking, where you have to actually analyse mathematical problems, such as, word sums, are very difficult' (OT2, 16 years of experience, private practice and mainstream schools). Occupational therapist 1 further identified difficulties with spatial perception, which may negatively impact on writing and result in the reversal of letters or numbers and incorrect spelling. Occupational therapist 2 added that learners with DCD may have difficulty in tracking across a page when reading, may skip over words or find the spacing between words challenging when reading and writing. A literal use of language, difficulty identifying rhyming words and learning letter blends may further impact on comprehension skills (RT1).

\section{Discussion}

The key findings of this study included the lack of understanding of teachers and other professionals, in effectively recognising the impact of DCD and its multidomain cascade effect in the life of Phase learners. This 
was especially evident in the confusion around even the name by which to call this set of symptoms and the difficulties in obtaining an accurate diagnosis. The lack of understanding of DCD is not unique to the South African context. Similar lack of understanding was identified in Canada (Jasmine, Tétreault \& Joly 2014; Rivard et al. 2007). However, within the South African context, and with the implementation of the screening, identification, assessment and support (SIAS) Policy (DBE 2014), the importance of teachers being able to recognise various special needs, including $D C D$, is imperative in order to provide the required classroom-based support.

Although DCD is classified as a motor disorder according to the DSM 5 (APA 2013), the impact of the disorder is farreaching. The multidomain impact of DCD, coupled with the cascade effects (Sadock et al. 2015; Surgen 2018), result in teachers being able to recognise the effects of DCD in all domains of functioning within in classrooms.

Fine and gross motor challenges of DCD may be recognised by Foundation Phase teachers. These observable difficulties include difficulty in doing zips and buttons, tying shoelaces, poor ball skills, unbalanced gait, clumsy playing, messy desks, being highly accident prone, poor fine motor skills, illegible handwriting, difficulty cutting and pasting and concerted avoidance of physical and sporting activities (Ball 2002; Case-Smith 2005; Cermak \& Larkin 2002; Farmer et al. 2016; Kranowitz 2005; MacIntyre 2001; Missiuna 2003; Prunty et al. 2016b; Sadock et al. 2015; Zwicker et al. 2018).

Challenges of low social interaction, lowered self-esteem, frustration, aggression, anxiety and task avoidance have been noted in previous studies (Crane et al. 2017; Farmer et al. 2016; Missiuna et al. 2007; Van Den Heuvel et al. 2016; Zwicker et al. 2018). Although the participants in this study did not allude to any gender differences observable in the social, emotional and behavioural domains, Li et al. (2018) have suggested that the learner's gender may play a role in regulating the emotional challenges experienced, with girls being more resilient to the cascading effect of DCD than boys.

Obstacles in planning, sequencing and organisation of daily living tasks are recognisable (Alloway 2007; Ball 2002; Missiuna et al. 2007; Prunty et al. 2016b) along with slow task completion and processing speed (Farmer et al. 2016; Sumner, Pratt \& Hill 2016). Cognitive challenges and academic delays (Bernard et al. 2018; Pieters et al. 2012) may result in the inaccurate labelling of an intellectual difficulty (Farmer et al. 2016) and thus the learner should be referred to a professional for an accurate diagnosis (Missiuna, Rivard \& Bartlett 2006).

Although all participants in the study displayed some understanding of DCD, they had fragmented knowledge of the full profile of the condition. Only the three physiotherapists consistently referred to DCD by the correct term. The collective participation of occupational, speech, remedial and physiotherapists and educational psychologists in this study contributed to a more holistic and in-depth understanding of
DCD symptomology, which can be identified by teachers. Cross disciplinary collaboration and training is necessary along with the purposeful sharing of research and resources across multidisciplinary services in order to develop and further an inclusive understanding of DCD.

For Foundation Phase teachers to recognise learners who have DCD, teachers need an awareness of the clusters of symptoms that could be displayed. These symptoms can be observed both within the classroom and on the playground and persistently and significantly interfere with the learners everyday functioning (APA 2013). To effectively screen for and identify the barriers to learning associated with DCD, it is necessary to recognise the effects of DCD on all domains of functioning.

The symptoms of DCD are generally recognisable within the classroom setting, making it possible for teachers to readily identify learners at risk, provided they show empathy and understanding towards developmentally diverse abilities. An empathic response to the difficulties of the 'clumsy' or 'messy' child contributes to acceptance of the learner's diverse abilities. Teachers should make early referrals to occupational or physiotherapists who can confirm the condition. Working closely with the learner's parents also aids the identification of these hidden neurological difficulties.

\section{Acknowledgements Competing interests}

The authors have declared that no competing interests exist.

\section{Authors' contributions}

Both authors contributed equally to this work. The data is based on N.L.W.'s Master's dissertation, supervised by J.V.F.

\section{Funding information}

This research received a specific grant as part of the Teaching and Learning Development Capacity Improvement Programme, which is being implemented through a partnership between the Department of Higher Education and Training and the European Union.

\section{Data availability statement}

Data sharing is not applicable to this article.

\section{Disclaimer}

The views and opinions expressed in this article are those of the authors and do not necessarily reflect the official policy or position of any affiliated agency of the authors.

\section{References}

Alloway, T.P., 2007, 'Working memory, reading and mathematical skills in children with developmental coordination disorder', Journal of Experimental Child Psychology 96(1), 20-36. https://doi.org/10.1016/j.jecp.2006.07.002 
American Psychiatric Association (APA), 2013, Diagnostic and statistical manual of mental disorders, 5th edn., American Psychiatric Association, Washington, DC. mental disorders, 5th edn., American Psychiatric As
https://doi.org/10.1176/appi.books.9780890425596

Ball, M.F., 2002, Developmental coordination disorder: Hints and tips for the activities of daily living, Jessica Kingsley Publishers, London.

Bernard, M., Leonard, H.C., Hills, E.L., Botting, N. \& Henry, L.A., 2018, 'Executive functions in children with developmental coordination disorder: A 2-year followup study', Developmental Medicine and Child Neurology 60(3), 306-313. https:// doi.org/10.1111/dmcn.13640

Biotteau, M., Chaix, Y. \& Albaret, J., 2016, 'What do we really know about motor learning in children with developmental coordination disorder?', Current Developmental Disorders Reports 3(2), 152-160. https://doi.org/10.1007/ s40474-016-0084-8

Caelli, K., Ray, L. \& Mill, J, 2003, 'Clear as mud: Towards greater clarity in generic qualitative research', International Journal of Qualitative Methods 2(2), 1-13. https://doi.org/10.1177/160940690300200201

Case-Smith, J., 2005, Occupational therapy for children, Elsevier Mosby, St. Louis, MO.

Cermak, S. \& Larkin, D. (eds.), 2002, Developmental coordination disorder, Delmar Thomson, New York, NY.

Chang, E.Y., 2018, 'Unveiling issues limiting participation of children with developmental coordination disorder: From early identification to insights for intervention', Journal of Developmental Physical Disabilities 30(3), 373-389. https://doi.org/10.1007/s10882-018-9591-3

Crane, L., Sumner, E. \& Hill, L.H., 2017, 'Emotional and behavioural problems in children with developmental coordination disorder: Exploring parent and teacher reports', Research in Developmental Disabilities 70, 67-74. https://doi.org/ 10.1016/j.ridd.2017.08.001

Department of Basic Education, 2014, Policy on screening, identification, assessment and support, Department of Basic Education, Pretoria.

Donald, D., Lazarus, S. \& Moolla, N., 2014, Educational psychology in social context, 5th edn., Oxford University Press Southern Africa, Cape Town.

Edmonds, C., 2013, 'Why teachers need to hear the voice and experience of the child with dyspraxia', Research in Teacher Education 3(1), 5-10.

Farmer, M., Echenne, B. \& Bentourkia, M., 2016, 'Study of clinical characteristics in young subjects with developmental coordination disorder', Brain \& Development 38(6), 538-547. https://doi.org/10.1016/j.braindev.2015.12.010

Finestone, M., 2004, 'Behaviour', in I. Eloff \& L. Ebersöhn (eds.), Keys to educational psychology, pp. 64-82, UCT Press, Cape Town.

Fourie, J.V., 2018, 'Teacher collaboration and working with school based support teams', in I. Eloff \& E. Swart (eds.), Understanding educational psychology, pp. 288-294, Juta Publishers, Cape Town.

Gibbs, J., Appleton, J. \& Appleton, R., 2007, 'Dyspraxia or developmental coordination disorder? Unravelling the enigma', Archives of Disease in Childhood 92(6), 534-539. https://doi.org/10.1136/adc.2005.088054

Gomez, A. \& Sirigu, A., 2015, 'Developmental coordination disorder: Core sensory motor deficits, neurobiology and etiology', Neuropsychologia 79(Pt B), 272-287. https://doi.org/10.1016/j.neuropsychologia.2015.09.032

Jasmin, E., Tétreault, S. \& Joly, J., 2014, 'Ecosystemic needs assessment for children with developmental coordination disorder in elementary school: Multiple case studies', Physical and Occupational Therapy in Pediatrics 34(4), 424-442. https:// doi.org/10.3109/01942638.2014.899284

Jasmin, E., Tétreault, S., Lariviére, N. \& Joly, J., 2018, 'Participation and needs of children with developmental coordination disorder: Perceptions of children and children with developmental coordination disorder: Perceptions of children and
parents', Research in Developmental Disabilities 73, 1-13. https://doi.org/ parents', Research in Develo
$10.1016 /$ j.ridd.2017.12.011

Kranowitz, C.S., 2005, The out-of-sync child, Penguin Group, New York, NY.

Le Roux, M., 2018, Praxis made practical, course titled: Praxis made perfect, Conducted by Professional Minds, Johannesburg.

Li, Y., Kwan, M.Y.W., Clark, H.J., Hay, J., Faught, B.E. \& Cairney, J., 2018, 'A test of the environmental stress hypothesis in children with and without developmental coordination disorder', Psychology of Sport \& Exercise 37, 244-250. https://doi org/10.1016/j.psychsport.2017.11.001

MacIntyre, C., 2001, Understanding and supporting children affected by dyspraxia/ $D C D$ in early years: Guidance for teachers, Afasic, Scotland.

Marien, P., Wackenier, P., De Surgeloose, D., De Deyn, P.P. \& Verhoeven, J., 2010 'Developmental coordination disorder: Disruption of the cerebello-cerebral 'Developmental coordination disorder: Disruption of the cerebello-cerebral
network evidenced by SPECT', The Cerebellum 9(3), 405-410. https://doi. network evidenced by SPECT',
org/10.1007/s12311-010-0177-6
Martorell, G., Papalia, D.E. \& Feldman, R.D., 2013, A child's world. Infancy through adolescence, 13th edn., The McGaw-Hill Companies, New York, NY.

Missiuna, C., 2003, Children with developmental coordination disorder: At home and in the classroom, CanChild Centre for Childhood Disability Research, McMaster University School of Rehabilitation Science, Ontario.

Missiuna, C., Gaines, R., Soucie, H. \& McLean, J., 2006, 'Parental questions about developmental coordination disorder: A synopsis of current evidence', Paediatrics Child Health 11(8), 507-512. https://doi.org/10.1093/pch/11.8.507

Missiuna, C., Moll, S., King, S., King, G. \& Law, M., 2007, 'A trajectory of trouble: Parents' impressions of the impact of developmental coordination disorder', Physical \& Occupational Therapy in Pediatrics 27(1), 81-101. https://doi. Physical \& Occupational Ther
org/10.1080/J006v27n01_06

Missiuna, C., Rivard, L. \& Bartlett, D., 2006, 'Exploring assessment tools and the target intervention for children with developmental coordination disorder', Physical and Occupational Therapy in Pediatrics 26(1), 71-89. https://doi.org/10.1300/ and Occupation

Pieters, S., Desoete, A, Van Waelvelde, H., Vanderswalmen, R. \& Roeyers, H., 2012 'Mathematical problems in children with developmental coordination disorder', Research in Developmental Disabilities 33(4), 1128-1135. https://doi.org/10.1016/j. ridd.2012.02.007

Polatajko, H.J., Fox, A.M. \& Missiuna, C., 1995, 'An international consensus on children with developmental coordination disorder', Canadian Journal of Occupational Therapy 62(1), 3-6. https://doi.org/10.1177/000841749506200101

Prunty, M., Barnett, A.L., Wilmut, K. \& Plumb, M., 2016a, 'Visual perceptual and handwriting skills in children with developmental coordination disorder', Human Movement Science 49, 54-65. https://doi.org/10.1016/j.humov 2016.06.003

Prunty, M., Barnett, A.L., Wilmut, K. \& Plumb, M., 2016b, 'The impact of handwriting difficulties on compositional quality in children with developmental coordination disorder', British Journal of Occupational Therapy 79(10), 591-597. https://doi. org/10.1177/0308022616650903

Rivard, L., Missiuna, C., Hanna, S. \& Wishart, L., 2007, 'Understanding teachers' perceptions of the motor difficulties of children with developmental coordination disorder (DCD)', British Journal of Educational Psychology 77(1), 633-648. https:// doi.org/10.1348/000709906X159879

Sadock, B.J., Sadock, V.A. \& Ruiz, P., 2015, Kaplan and Sadock's synopsis of psychiatry: Behavioural sciences/clinical psychiatry, International Edition, 11th edn., Wolters Kluwer, Philadelphia.

Schott, N., El-Rajab, I. \& Klotzbier, T, 2016, 'Cognitive-motor interference during fine and gross motor tasks in children with developmental coordination disorder', Research in Developmental Disabilities 57, 136-148. https://doi.org/10.1016/j. ridd.2016.07.003

Speedtsberg, M.B., Christensen, S.B., Andersen, K.K., Bencke, J., Jensen, B.R. \& Curtis, D.J., 2017, 'Impaired postural control in children with developmental coordination disorder is related to less efficient central as well as peripheral control', Gait \& Posture 51(1), 1-6. https://doi.org/10.1016/j.gaitpost.2016. 09.019

Sumner, E., Pratt, M.L. \& Hill, E.L., 2016, 'Examining the cognitive profile of children with developmental coordination disorder', Research in Developmenta Disabilities 56, 10-17. https://doi.org/10.1016/j.ridd.2016.05.012

Surgen, D., 2018, 'Developmental coordination disorder and its cause: The road less travelled', Human Movement Science 57, 501-504. https://doi.org/10.1016/j. humov.2017.04.006

Van Den Heuvel, M., Jansen, D.E.M.C., Reijenveld, S.A., Flapper, B.C.T. \& SmitsEngelsman, B.C.M., 2016, 'Identification of emotional and behavioral problems by teachers in children with developmental coordination disorder in the schoo community', Research in Developmental Disabilities 51-52, 40-48. https://doi. org/10.1016/j.ridd.2017.12.014

Yam, T.T. \& Fong, S.M., 2018, 'Leg muscle activation patterns during walking and leg lean mass are different in children with and without developmental coordination disorder', Research in Developmental Disabilities 73, 87-95. https://doi. org/10.1016/j.ridd.2017.12.014

Zwicker, J.G., Suto, M., Harris, S.R., Vlasakova, N. \& Missiuna, C., 2018, 'Developmental coordination disorder is more than a motor problem: Children describe the impact of daily struggles on their quality of life', British Journal of Occupational Therapy 81(2), 65-73. https://doi.org/10.1177/030802261 of Occup
7735046 